Published as Cantwell , R. \& Scevak, J. 2004). Engaging university learning: the experiences of students entering university via recognition of prior industrial experience. Higher Education Research and Development . 23(2), $131-145$.

Engaging university learning: the experiences of students entering university via recognition of prior industrial experience ${ }^{1,2,3}$

Robert H. Cantwell \& Jill J. Scevak

School of Education

University of Newcastle

Running header: Engaging university learning

Address for correspondence

Dr Robert Cantwell

School of Education

University of Newcastle,

University Drive

Callaghan, NSW

Australia, 2308

Phone 0249216735

Fax 0249216895

Email robert.cantwell@newcastle.edu.au 


\section{Engaging university learning: the experiences of students entering university via recognition of prior industrial experience}

In this study, the academic experiences of 33 male students from an industrial background were investigated as they completed a two year education degree. The purpose of the study was to investigate the quality of student adjustment to an academic environment following extensive industrial training and experience. Students completed a series of questionnaires relating to learning as well as a series of open ended questions relating to academic and social adjustment. Data indicated that while students had developed a positive learning profile, a continued belief in the structural simplicity of knowledge appeared to have a significant diminishing effect on the quality of adjustment and on the quality of learning outcomes. Open ended responses revealed patterns of academic adjustment consistent with the restricted understanding of the nature of university learning. Implications of these data for both RPL entry and ongoing support are broached.

During an introductory class on "Professional Preparation for Teaching”, students were asked to think of a topic of interest and to develop a series of objectives that might underlie the teaching of that topic. Among the class were a group of students undertaking a shortened course in teacher training based upon their prior experience as tradesmen in industry. One of the students, from a metalworking background, determined that he would prepare a lesson on "making a toolbox" - a typical task in junior secondary design and technology. When asked to explain the major purpose behind the activity of building a toolbox, the student replied that it was clearly to “carry tools around”. When probed for further objectives, the student was at a loss to conceptualise what learning beyond the processes involved in construction could be an outcome of the exercise. A discussion ensued in which several other potential outcomes identified - understanding of the properties of metal, understanding the principles behind hinge selection and use, and so forth. It was then suggested that these might not only be measurable outcomes of the activity, but might also provide the basis for further studies of fabrication with metal, thus providing a conceptual knowledge base upon which deeper understanding could be built. The student readily identified with these possible outcomes. Tellingly, his comment was to the effect "Wow - they never explained it to us like that in TAFE".

What implications are there to this anecdote? It would seem first and foremost that while highly motivated, the student's engagement with the learning context, as with most novitiate teacher education students, was premised on a somewhat limited conception of what learning entailed and of where the possibilities of learning could be taken. Their limited tertiary education experiences would be likely to be associated with a relatively naive conception of learning and knowing - one which could be reasonably expected to assume more sophisticated forms through continued higher education. However, in this instance, aspects of the student's background may also act as mediating influences. Like an increasing number of students undertaking teacher education programmes in Australia, this student obtained entry into a shortened programme based upon a recognition of prior learning and experience (RPL) in a cognate field. In this instance, the student entered the Bachelor of Education (Design \& Technology) degree from a metalworking trades background as part of a retraining package following the closure of a major industry. 
In a recent paper, Trowler (1996) raised concerns about the degree to which entry via RPL in the British context has been able to balance accreditation of relevant experience with the need to recognize the unique demands of learning in a university context. Most salient in this context is the level and abstraction of the knowledge to be acquired and understood relative to other forms of post compulsory education. As Trowler (1996) has noted, there are significant epistemological and cultural factors potentially impinging on the success of RPL students:

What candidates are effectively being asked to do is to convert practical knowledge ... into a form of propositional knowledge which is conceptual, explicit, coherent and organised along disciplinary lines ... (p20)

Implicit in Trowler's (1996) contention is that there are significant qualitative differences in the kind of knowledge expected of students learning in a university environment, and the kind of knowledge more typically associated with other contexts. In a similar vein, Rawson (2000) questions the applicability of essentially “skills" based curricula to the espoused objectives of depth of personal learning typical of university learning (also Biggs \& Collis, 1989; Billet, 2001).

Debate reasonably exists, therefore, as to whether there are specific issues of concern that may separate RPL entry students from not only mainstream school leavers but also from other non-traditional entry adult students. There is certainly a wealth of evidence pointing to the success of mature aged entry students in the university system (Archer, Cantwell \& Bourke, 1999; Cantwell, Archer \& Bourke, 2001; Hoskins, Newstead \& Dennis, 1997; Richardson, 1994). Much of this research, however, has focused on mature aged students entering university via some form of preliminary or enabling programme. These programmes normally require potential mature aged students to complete a university-based preliminary year of study as a prelude to undergraduate entry. For these students, orientation to university study (both epistemologically and culturally) is generally an explicit component of the enabling course, thus providing a platform from which subsequent undergraduate study can spring. Our own research, for example, indicates an extremely strong undergraduate performance amongst those mature aged students who successfully matriculate from these enabling courses (Cantwell et al., 2001; also Hoskins et al, 1997).

For students entering university directly via RPL, however, there is a generally tacit presumption that the developmental changes typically associated with completion of enabling study are in fact present on enrolment that the prior learning in cognate fields has seen, a priori, the construction of an appropriate representation of the discipline among RPL students. Trowler (1996) sees in this kind of reasoning three problematic assumptions. These include a failure to identify the ontological limitations to the presumed everyday learning; the presumption of reflectivity in everyday experience; and the presumption that the reflection that does occur is necessarily equivalent to the assumed requirements for university study. 
Given the problematic nature of the assumptions underpinning RPL enrolment, the present study aims to evaluate the degree to which RPL students are prepared for university study, both upon entry and through the experience of university. In particular, we refer here to three particular domains of metacognitive knowledge that we argue underpin Trowler’s (1996) three problematic assumptions of RPL. It may reasonably be argued that the quality of reflectivity emerges from an interaction between the understandings of the nature and limitations of knowledge and knowledge acquisition; understandings of the quality and form of motivation driving the use of particular categories of learning strategies; and understandings of the nature of complexity underlying learning and of the potential mechanisms for orchestrating such learning. As Cantwell (2001) has argued, these kinds of metacognitive knowledge manifest in the individual learner in the form of dispositions in a sense as internalised and overlearned patterns of response to challenging learning situations. That is, how we determine the form of engagement in learning is reflective of our own constructed metacognitive knowledge - our individually constructed “text book” of learning providing the explanations of our prior learning and directions for resolving the challenges of current and future learning.

For the RPL students involved in the present study we hypothesize that the salient metacognitive knowledge brought to the context of university study will be most reflective of prior trade learning and practise with its greater focus on the acquisition of skills and competencies, and more limited opportunities for independent learning. This, we suggest, will manifest primarily in a qualitatively different understanding of the nature of knowledge as the object of both analysis and acquisition. Following Schommer's (1993) conceptualisation of epistemological knowledge, we distinguish between the form and structure of knowledge (as indicated by Schommer's description (in the less developed form) of knowledge as both simple in structure and certain in form) on the one hand, and the presumptions of process underlying the acquisition of knowledge (again in the less developed form, belief in innate ability and quick learning). We hypothesise that the industrial experience of the trade background RPL students is likely to engender a view of knowledge that sees knowledge acquisition as both effortful and subject to individual skill development. What is more problematic in our view, and where the background experiences may lead to different constructions from those evident in entering students from school and university-based enabling programmes, is the translation of understandings of the form and structure of knowledge from industry to academia. The possibility of disjuncture between the understanding of the process of knowledge acquisition and understanding of the object of those processes presents a potentially powerful barrier to effective transition to university study. This possibility in turn relates a potentially paradoxical disjuncture between motivational states and perceptions of the object of learning. Typically mature aged students at university present, in Biggs' (1987a) terms, with predominantly deep learning intentions (Archer et al, 1999; Richardson, 1994). That is to say, mature aged students, to a significantly greater extent than younger university students, are motivated by a desire for personal fulfilment, and tend to adopt learning strategies consistent with the desire to construct personally meaningful representations of the knowledge to be learned. Not surprisingly, then, mature aged students also typically report a greater willingness to adaptively respond (in Cantwell \& Moore’s (1996) terms) to the strategic demands of learning. The paradox, however, lies in the potential disjuncture between expressed motivational and self-regulatory dispositions and the naivety of 
the initial understanding of the object of learning - that is in the structure and form of knowledge to be engaged and understood. In a qualitative sense, the conception of deep learning underlying these students' approach to learning, and the strategic flexibility acknowledged as necessary to achieve this, may be restricted in enactment by the enduring, but naive "practical knowledge" emanating from the industry background. That is to say, the epistemological assumptions may impose limits on the perceived depth to which it is possible to take "knowing".

In summary, we aim in this study to examine the relationships between the qualities of metacognitive knowledge brought to university study by a specific group of mature aged learners - those entering under RPL from an industrial background - as potential mediators of both the quality of adjustment to university study and to academic achievement.

\section{Method}

Subjects: The study included 33 students who had entered into a two year Bachelor of Education (Design \& Technology) course on the basis of prior industrial experience (see Box 1). All respondents were male. Mean age of participants was 39 years (sd. 7.50), ranging from 28 to 56 years. Twenty-three of the participants were married, 10 were single. Prior to obtaining their trade qualification, 22 of the students completed a secondary education up to Year 10, while a further 11 completed secondary education up to Year 12 . Twenty-four of the participants had obtained trade qualifications in the metal trades, with the remaining nine spread across a variety of trade areas. Mean length of time in these occupations was 14.18 years (sd. 7.79 years). Seven of the participants had begun their study in 1998; 12 in 1999, 7 in 2000 and 7 in 2001. Twenty-two of the students were sponsored under the retraining programme provided by BHP Steel following its closure, while the remaining eleven students were private enrolments.

External: RPL Entry Credit Granted in 130 Credit Points on the basis of Subjects Studied as a Whole of Fitting and Turning (Fitting Strand) Trade Qualification at TAFE Together with Evidence of Demonstrated Substantial Industry Experience and Professional Development and/or Additional Studies.

External: Undergraduate Study is in the Areas of Technics, Technical Drawing, Industrial Technology, Design \& Technology

Box 1: RPL accreditation on a student transcript

\section{Materials}

Materials for the study consisted of a demographic information sheet, three questionnaires and a series of openended questions. Demographic information sought included age, marital status, prior schooling, trade background, years in previous occupation, sponsorship and year of enrolment. Three questionnaires relating to aspects of learning were provided.

Schommer’s (1993; 1998) Epistemological Beliefs Questionnaire was included as a measure of student 
understanding of the nature of knowledge. Schommer (1993) argues that how individuals think about the issues of "What is knowledge?" and "What is involved in knowing?" involves us in consideration of four aspects of individual beliefs about knowledge. Two of these beliefs relate to the nature of knowledge itself. The first concerns the structure of knowledge - whether the individual sees their own actual or potential knowledge as definable in simple "packages" (a quantitative conception) or whether more complex interrelationships are involved (a more qualitative conception) (eg. Things are simpler than most lecturers would have you believe). The second dimension relates to the possibility that what we know may only represent a part of what is possible to know - that is, whether our conception of knowledge is tied to the possibility that knowledge may grow and change in form and structure, that it may be inherently uncertain (eg. The only thing that is certain is uncertainty itself). The second two aspects referred to by Schommer refer to the possibilities in acquiring knowledge. On the one hand, an individual may see knowledge acquisition as the product of strategic behaviour. Therefore the quality of knowledge acquired will represent the quality of mental processes used in its acquisition. If however, the individual sees his or her own capacity to acquire knowledge as fixed by an innate ability, then knowledge acquisition will not be linked to changes in strategic behaviours (eg. Going over and over a difficult textbook chapter usually won't help you understand it). Finally, Schommer suggests that individuals may conceptualise knowledge acquisition as the product of effortful and time consuming activity - that what is being acquired is of such complexity and abstraction that time and effort become critical to learning. Other individuals, however, may see time spent as unrelated to knowledge acquisition: one either "gets it" immediately or not at all (eg. If you are ever going to be able to understand something, it will make sense to you the first time you hear it ). The version used was a shortened form of 42 items presented on a five point Likert Scale. Four beliefs about knowledge may be identified. In their less developed form these include a belief in Simple Knowledge, a belief in the Certainty of Knowledge, a belief in Innate Ability to acquire knowledge, and a belief in Quick Learning. Reliability estimates (Cronbach alpha) were acceptable for all scales (Belief in Innate Ability, .69; Belief in Simple Knowledge, .60; Belief in Quick Learning, .70; Belief in Certain Knowledge, .66).

Biggs' (1987b) Study Process Questionnaire was included as a measure of the underlying conception of learning driving engagement. The approach reflects an interaction of motivations and strategic choices. Three approaches may be identified: a Surface Approach, a Deep Approach and an Achieving Approach. These approaches represent distinct qualitative differences in how individuals are likely to engage their learning. Deep learners, for example, link depth of learning to the quality of strategic behaviours employed. This in turn represents a motivational state closely based upon intrinsically derived goals associated with task mastery ( $I$ find that at times studying gives me a feeling of deep personal satisfaction (motive) While I am studying, I often think of real life situations to which the material that I am learning would be useful(strategy)). Surface learners, by contrast, typically disassociate from the purpose of learning, giving greater emphasis to the instrumental goals associated with the outcomes. The bias amongst such learners is towards avoidance of failure rather mastery of the task (eg. I chose my present courses largely with a view to the job situation when I graduate rather than out of their intrinsic interest to me (motive) I think browsing around is a waste of time, so I only study seriously what is given out in class or in the course outlines (strategy)). The achieving approach, which 
may link closely (although differentially) with either the deep or surface approach, is more biased towards a competitive attainment of institutional objectives (eg. I have a strong desire to excel in all my studies (motive) After a lecture or tutorial I reread my notes to make sure they are legible and that I understand them (strategy)). The questionnaire includes 42 items presented on a five point Likert scale. Reliability estimates for the three scales were acceptable (Surface approach, .60; Deep approach, .81; Achieving approach, .81).

Cantwell and Moore's (1996) Strategic Flexibility Questionnaire provided a measure of the manner in which students metacognitively deal with issues of complexity in learning. University learning involves mastery of complex content and complex arrays of strategies. Individuals need to be aware of the need to orchestrate the demands of complex content and strategy use in task appropriate ways (eg. Before starting work on a particular problem I like to play with a number of possible ways of attacking the problem). For some individuals, the complexity is resolved not be adaptive responses, but rather by recourse of tried and trusted routines - whether or not these routines are appropriate to the task at hand (eg. Once I have found a satisfying way of approaching my study, I feel it is safest to stick with this method). Other individuals may readily recognise the need for responding to complexity, but find significant difficulty in formulating and implementing appropriate plans to overcome the complex processing demands confronting them (eg. I often find the ideas and methods I come across when preparing for an assignment more confusing than helpful). The questionnaire includes 21 items presented on a five point Likert scale. Three self-regulatory orientations may be identified: an Adaptive selfregulatory orientation, and Inflexible self-regulatory orientation and an Irresolute self-regulatory orientation. Reliability estimates for the three scales were acceptable (Adaptive, .73; Inflexible, .73; Irresolute, .70).

Students were also asked to provide written responses to 10 open-ended questions addressing such concerns as expectations and feelings on enrolment, reactions to course participation, feelings towards the support mechanisms available, and perceptions of any change in motivation and goal.

Finally, academic achievement information was obtained from university records in the form of a cumulative 7point GPA. The GPA is calculated on the basis of academic grade achieved in individual subjects weighted by the credit point allocation for that subject. Subjects attracting an Ungraded Pass (such as teaching practices) are not included in the calculation of the GPA. A High Distinction equals a seven, Distinction equals a six, a Credit a five, a Pass a four, and a Fail a zero. The mean GPA for subjects in this study was 4.42 (sd 1.09, range 2.21 6.69), representing a pass average.

\section{Procedures:}

Students received the questionnaires as a package in normal class time. After explaining the purpose of the study and obtaining informed consent, students completed the questionnaires at home and returned them by mail to the researchers. Approximately 50 questionnaires were distributed, with 33 returned. 


\section{Results}

We examine firstly the profile of the respondents as a group. By way of comparison, data from comparison populations are included. The sources of these comparative data are indicated in the various tables. All statistical analyses were conducted using Statistica for Windows, v6, (StatSoft Inc., 2001).

Epistemological beliefs: Scale mean responses to the Epistemological Beliefs Questionnaire are included in Table I. It should be remembered that the lower the score, the more developed the epistemological belief. A repeated measures ANOVA indicated significant differences in the pattern of responses to the epistemological belief scales $\left(F_{3,96}=39.20, p<.001\right)$ Post hoc Scheffé analysis indicated a significantly less developed Belief in Simple Knowledge compared to all other scales. That is, while these students held relatively developed understandings about the active and effortful manner in which knowledge is acquired, they reported slightly less developed understandings of the tentativeness of that knowledge, and significantly less developed understandings of the structure of that knowledge. The comparative data indicated that a sample of

Table I: Comparison of the reported epistemological beliefs of RPL students with those of other selected groups

\begin{tabular}{rrrrr}
\hline & $\begin{array}{r}\text { RPL Industry } \\
(\text { current data }) \\
(\mathrm{n}=33)\end{array}$ & $\begin{array}{r}\text { Under 20 } \\
\text { Undergraduates } \\
(\mathrm{n}=55)^{1}\end{array}$ & $\begin{array}{r}\text { Over 25 } \\
\text { Undergraduates } \\
(\mathrm{n}=66)^{1}\end{array}$ & $\begin{array}{r}\text { Practising } \\
\text { Teachers } \\
(\mathrm{n}=184)^{2}\end{array}$ \\
\hline Quick learning & 2.26 & 3.05 & 2.95 & 2.05 \\
Innate Ability & 2.17 & 2.43 & 2.42 & 2.05 \\
Certain Knowledge & 2.41 & 2.45 & 2.40 & 2.18 \\
Simple Knowledge & 2.92 & 2.19 & 2.10 & 2.36 \\
\hline
\end{tabular}

\footnotetext{
${ }^{1}$ data sourced from Cantwell \& Hempenstall (2001)

${ }^{2}$ data sourced from Scevak, Cantwell \& Chan (2002)
}

both younger and older undergraduate arts students (Cantwell \& Hempenstall, 2001) tended to see knowledge as relatively complex, but were less developed in relation to both the certainty of knowledge and the processes by which knowledge is acquired. Practising teachers, on the other hand, tended to report more highly developed beliefs across the board (Scevak, Cantwell \& Chan, 2002). We suggest that the pattern reflected by the RPL students is consistent with the essentially procedural knowledge typical of trade level education. The resilience of this conception of a simple structure to knowledge is reinforced in the comparison across time. Assuming homogeneity amongst the RPL group - that is a lack of cohort difference on initial enrolment - then any difference in the pattern of response to the epistemological questionnaire as a function of length of time at the university may well be taken as indicative of an institutional effect modifying epistemological beliefs. To test this proposition, a 3 (Number of semesters enrolled [1-2; 3-4; 5+]) X 4 (Epistemological belief scale) ANOVA was conducted. The analysis revealed no significant effect for semesters enrolled on epistemological belief $(F$ $2,30=0.07, \mathrm{~ns})$ nor was there an interaction between semesters enrolled and specific epistemological belief $\left(F_{6,90}\right.$ 
$=0.26, \mathrm{~ns})$. In other words, these students retained a belief in the essential simplicity of knowledge despite exposure to quite complex and abstract theoretical material in the course of their study.

Approaches to Learning. Scale means from responses to the Study Process Questionnaire are included in Table II. A repeated measures ANOVA indicated significant differences in the pattern of response to this questionnaire $\left(F_{2,64}=5.02, p<.01\right)$. Post hoc Scheffé testing revealed scores on the Deep approach to be significantly higher than scores on the Surface approach. This finding is consistent with expectations for mature aged students, as for example, the pattern of response of mature aged enabling students in Cantwell and Grayson’s (2002) data. A 3 (Semesters enrolled) X 3 (Approach scale) ANOVA revealed no significant change in the pattern of response as a function of year of enrolment ( $F_{4,60}=1.72$, ns). In summary, RPL students appear to maintain a bias towards a deeper approach to learning over the duration of their study.

Table II: Comparison of the reported approaches to learning of RPL students with those of other selected groups

\begin{tabular}{rrrrr}
\hline & $\begin{array}{r}\text { RPL Industry } \\
(\text { current data) } \\
(\mathrm{n}=33)\end{array}$ & $\begin{array}{r}\text { Enabling Students } \\
\text { aged under 21 } \\
(\mathrm{n}=131)\end{array}$ & $\begin{array}{r}\text { Enabling students } \\
\text { aged over 21 } \\
(\mathrm{n}=58)\end{array}$ & $\begin{array}{r}\text { Enabling } \\
\text { students entering } \\
\text { via TAFE based } \\
\text { ceertificate }^{1} \\
(\mathrm{n}=28)\end{array}$ \\
\hline Surface Approach & 3.12 & 3.36 & 3.08 & 3.37 \\
Deep Approach & 3.49 & 3.08 & 3.34 & 3.03 \\
Achieving Approach & 3.25 & 3.25 & 3.21 & 3.19 \\
\hline
\end{tabular}

${ }^{1}$ data sourced from Cantwell \& Grayson (2002)

Self-regulatory control. Scale mean responses to the Strategic Flexibility Questionnaire are included in Table III. Repeated measure ANOVA indicated a significant difference in the pattern of response to the SFQ items ( $F$ $2,64=3.57, p<.05)$. Post hoc Scheffé testing indicated a near significant $(p<.1)$ bias towards adaptive control processes above both inflexible and irresolute control. No effect for semesters enrolled was evident in the pattern of responses $\left(F_{4,60}=0.37\right.$, ns). In summary, like other mature aged undergraduates (Cantwell \& Hempenstall, 2001), the respondents appear to adopt a functional self-regulatory profile that is maintained for the duration of their study.

Table III: Comparison of the reported approaches to self-regulatory control of RPL students with those of other selected groups

\begin{tabular}{rrrr}
\hline & $\begin{array}{r}\text { RPL Industry } \\
(\text { current data) } \\
(\mathrm{n}=33)\end{array}$ & $\begin{array}{r}\text { Under 20 } \\
\text { Undergraduates } \\
(\mathrm{n}=55)^{1}\end{array}$ & $\begin{array}{r}\text { Over 25 } \\
\text { Undergraduates } \\
(\mathrm{n}=66)^{1}\end{array}$ \\
\hline Adaptive control & 3.37 & 3.07 & 3.30 \\
Inflexible control & 3.03 & 3.11 & 3.16
\end{tabular}


Irresolute control

${ }^{1}$ data sourced from Cantwell \& Hempenstall (2001)

Academic achievement. At a purely descriptive level, approximately one-third of the respondents (10 students) achieved a GPA of less than 4.00 - that is, a failure level. A further one-third (10 students) achieved a pass level GPA, while the remaining third achieved at a credit level (10 students) or higher (2 students). The relationships between the measures of individual differences and academic achievement were assessed using zero-order correlations. These are included in Table IV. Due to the limitations of the sample size, only two of the measures yielded significant relationships with academic achievement: a Belief in Simple Knowledge and Irresolute Strategic Control were both significantly associated with poorer academic performance. Nonetheless, other relationships were substantial if non-significant. Positively associated with academic achievement were a Deep Approach, more sophisticated epistemological beliefs and both Adaptive and Inflexible Strategic Control. Surface Approach was negatively associated with academic outcomes.

Table IV: Zero-order correlations between measures of individual differences and academic achievement

\begin{tabular}{lc}
\hline & GPA \\
\hline Surface Approach & -.23 \\
Deep Approach & .32 \\
Achieving Approach & .13 \\
Belief in Innate Ability & -.21 \\
Belief in Simple Knowledge & $-.36^{*}$ \\
Belief in Quick Learning & -.31 \\
Belief in Certain Knowledge & -.32 \\
Adaptive Strategic Control & .22 \\
Inflexible Strategic Control & .28 \\
Irresolute Strategic Control & $-.41^{*}$ \\
\hline$* p<.05$ &
\end{tabular}

The data present a profile of RPL students that in a number of ways is typical of mature aged students returning to university study (Archer, Cantwell \& Bourke, 1999; Richardson, 1994). As a group, the RPL students report a deep approach to learning, an understanding that the processes of acquiring knowledge involve effortful and strategic behaviours, and an understanding that such learning may be facilitated by the flexible use of cognitive strategies. However, in two other areas the RPL group differed from the traditional mature aged student profile. These were to do with less developed understandings about the complex structure of knowledge, and the capacity to strategically orchestrate complex information. Clearly in relation to perceptions of the structural complexity of knowledge, and less so, but nonetheless notably so, in relation to the certainty of knowledge, little 
fundamental change had occurred. To a large extent, we argue this to be artefacts of the students' background in industry. That is to say, the nature of the technical training undertaken by these students, and the nature of their occupational experiences, both contribute to an epistemological framework in which knowledge (and task) may be conceived of in terms of less complex, often procedurally defined, structures. The nature of the work is rarely such as to explicitly encourage the transformation of everyday procedural knowledge into its more structurally complex underlying propositional form. Moreover, the experience of university learning appeared to do little to change this fundamental belief - hence a logical disjuncture between intent, assumptions of appropriateness in strategy use and assumptions of appropriateness in defining the object of learning on the one hand and outcome on the other. Such disjuncture may be presumed to manifest in the strong negative correlation between achievement and irresolute strategic control.

If we take, then, the notion of belief in the structural simplicity of knowledge as the pre-eminent belief of these students, and if we then utilise this belief as the fulcrum around which other beliefs and outcomes may be centred, then a potentially defining profile can be constructed. As may be identified in Table V, a belief in the structural simplicity of knowledge correlates strongly with a range of other individual differences and academic outcomes, including surface learning, a rejection of deep learning, a belief in quick learning and certain knowledge, a loss of strategic control over learning and poorer academic outcomes.

Table V: Relationships between a Belief in Simple Knowledge and other measures of individual differences

\begin{tabular}{lc}
\hline & $\begin{array}{r}\text { Belief in Simple } \\
\text { Knowledge }\end{array}$ \\
\hline Surface Approach & $.62^{*}$ \\
Deep Approach & $-.46^{*}$ \\
Achieving Approach & .14 \\
Belief in Innate Ability & $.35^{*}$ \\
Belief in Quick Learning & $.48^{*}$ \\
Belief in Certain Knowledge & $.62^{*}$ \\
Adaptive Strategic Control & $-.34^{*}$ \\
Inflexible Strategic Control & $.36^{*}$ \\
Irresolute Strategic Control & $.56^{*}$ \\
Academic achievement & $-.36^{*}$ \\
\hline$* p<.05$
\end{tabular}

Analysis of the open-ended questions provided some support for these conclusions. The two cases described below represent less successful adjustment to the experience of university study. While a number of students in the study completed the adjustment process with reasonable measures of success, $30 \%$ of those participating in 
the study achieved a failure level GPA. Our analysis of the questionnaire data indicated a significant relationship driving beliefs about learning and knowledge and less successful academic outcomes. These relationships are illustrated in the cases described below.

Case 31 presented as surface oriented with a belief in the structural simplicity of knowledge and seeing the regulatory demands of university learning in terms of either the application of known algorithms or the reporting of confusion in unravelling the complex demands of learning. The GPA achieved by this student was 2.21. In short, the student presented with an "at risk" profile and unsuccessful academic outcomes. For this student, the key to successful adjustment was to be in uncovering the "system” - in determining what routines and procedures would open the door to understanding and academic success. This was the measure of his success in industry:

I was the Boss. I knew my job and what was required of me and was reasonably confident in that. But uni you come in cold, don't know the system or anyone else. It's a whole new culture and learning curve. If you don't learn the system quickly I believe it would be easy to sink

By the end of his second semester, the student became somewhat frustrated with the "system" for its failure to reward effort:

Not fortunately satisfied with the way the system works. Failing an assignment did not impress me after the amount of work I had put into it

In this instance the students' attribution for potential success is totally linked to effort - here a quantitative conception that does not take into account the underlying need to qualitatively change the driving conception of knowledge that is ultimately limiting the students’ ability to conceptualise what indeed is required by university level learning. The increasingly frustration of the student reflected an increasing awareness that the systems that worked in the past were not working at university:

I think the difference from TAFE to uni is larger than I expected. Completing a Certificate IV course in Community Services (welfare) with distinction last year and then coming and so far looking at pass or possible credit is a big difference

Case 15 represented another illustrative example. Like Case 31, Case 15 presented with a clear belief in the structural simplicity of knowledge. However, where Case 31 linked this with a disposition towards surface learning and with confusion in strategic control, Case 15 was less clear in the driving approach to learning. The student reported as high on all approaches to learning. Further investigation revealed this to reflect a confusion of motive/strategy combinations. The student reported higher surface and achieving motives whilst at the same time endorsing both deep and achieving strategies. The combination is suggestive of an extrinsic motivation coupled with a high degree of competitiveness and organization, but which in turn are coupled with the less congruent meaning-centred strategies. Not surprisingly, then, the student also endorsed the need to be flexible in learning whilst simultaneously reporting uncertainty in strategic control. The initial reaction of this student to 
university learning, then, was also one of confusion:

When I first attended class I had no idea what to expect. I was feeling apprehensive about whether I was smart enough to be able to complete the course. ....

Tellingly, the students' later reactions (after four semesters) reflected the confusion of driving beliefs: the trade background appeared sufficient to cover the technical subjects involved in the Design and Technology curriculum, but was appearing dramatically less appropriate to dealing with the more theoretically oriented subjects:

I had no problems with my D \& T subjects. However, I did have problems with the [Psychology of Teaching] subject. I had problems writing in the style that was required... and hence I failed.

The student appeared to have a growing insight into the reasons for these difficulties - awareness of the need for more sophisticated study skills, increasing awareness of the gap between TAFE and university level study:

Study skills were lacking. I have always had good time management skills.... Self learning, not being spoon-fed information like previous [TAFE] studies.... At uni, the lecturers seemed to be operating on another planet

\section{Discussion}

Our major purpose in this study was to examine the relationships between the metacognitive attributes of students enrolling in university under RPL entry and their adjustment to the experience of university study. Based on earlier research (Archer et al, 1999; Cantwell et al, 2001; Cantwell \& Grayson, 2002) we hypothesised that in many respects the RPL students studied here would present with attributes typical of mature aged entry students in general - an orientation towards deeper learning coupled with a willingness to engage in active and adaptive self-regulation. At the same time, we further hypothesised, following Trowel's (1996) critique of RPL entry in the British context, that elements of the prior history of these students may act as a point of disjuncture for these students by imposing limits on the epistemological possibilities driving the students' learning.

The data gave support to these conjectures. The RPL students presented with a bias towards deeper learning and adaptive self-regulation. Moreover, while their epistemological beliefs acknowledged the role of effortful and strategic learning in acquiring knowledge, as a group the students also reported beliefs about the structure and form of knowledge consistent with the notion of a practical rather than propositional knowledge - that is a retained belief in the fundamental structural simplicity and certainty of knowledge. Most importantly, these dispositions endured over time, suggesting that these students did not fundamentally question or restructure their driving belief systems. Not surprisingly, the relationships between these beliefs and academic performance were in the directions predicted by theory. 
While it should be acknowledged that not all the RPL students involved in this study performed poorly - two thirds of the respondents achieved at a passing grade or higher - there are nonetheless concerning tendencies in the data. The enduring strength of the students' belief in the fundamental structural simplicity of knowledge, and the relationship between this belief and less functional learning dispositions and poorer academic outcomes is perhaps the issue of greatest concern emerging from the data. Several explanations for this may be offered, including within-individual factors, structural factors within the course itself and underlying cultural factors emerging from the common life-histories of these students

We would suggest that belief is amenable to change under two conditions: that the individual is open to change, and that the dissonance occurs under conditions that are both sympathetic to the affective consequences of belief change and sympathetic to the time frame required for belief change to occur. For these students it is reasonable to speculate that structural factors within the degree (eg. short time frame, higher than average workload, varied epistemological demands across subjects; lack of explicit support mechanisms) contributed to a lessening likelihood of individual change. This is not to suggest that the less functional beliefs about learning held by many of these students are not changeable. The simple anecdote reported at the beginning of this paper illustrates the possibility for such change (albeit over a more extended time frame than one informal conversation). Moreover, at no point are we suggesting that "general ability” factors may discriminate this group from other mature aged students. Rather, what we do suggest is that these students are being asked to confront more than many other students entering degree programs. They are being asked to internalise new ways of thinking about phenomena in a time frame that is between $50 \%$ and $75 \%$ of the time frame given to non-RPL students and to manage a workload that is up to $50 \%$ higher per semester. Moreover, as a point of future research, we suggest that cultural factors associated with the common workplace experiences (eg. trade background, relatively technical conceptions of teaching; influence of predominantly male work environments, hierarchical power structures in prior work environments and affective demands associated with retraining) may impact on the ability of the students to adjust to the higher-order academic demands of university level study. It may be the case that the limited time and support afforded in the degree to deconstruct entrenched beliefs acted as a barrier against the transformation of thinking among many of the participants. This speculation, however, does require further research.

The question to us is then twofold: are the RPL students, as a group, sufficiently prepared to undertake degree level study without some form of preparatory program, and is there sufficient support available in situ to ensure that these students are able to develop those skills and dispositions essential for success at university? In relation to the former question, we suggest that criteria for RPL may need to incorporate different kinds of requisite experiences (much along the lines of Trowler's (1996) critique) with a view to some form of bridging program. Previous research by Archer et al (1999), Cantwell and Grayson (2002) and Hoskins et al (1997) all point quite unambiguously to the later benefits of adult enabling courses on undergraduate study. In relation to the latter question, we suggest that where potential "at risk” factors may be readily identified (as in the case of 
RPL entry), some form of support beyond mere attendance at lecturers and tutorials may well be mandated. Whether this support take the form of formalised workshops or less formal study groups, it seems to us from a Vygotskian perspective that the fundamental changes in beliefs about learning required by many of these students mandates that some form of scaffolding be in place if the metacognitive knowledge driving these students' learning is to match the expectations of university level study.

\section{Notes}

1. This research was supported by a grant from the Griffith Duncan Fund, Faculty of Education, University of Newcastle

2. The authors wish to acknowledge the help of Alison Hunt in the conduct of this research

3. An earlier version of this paper was presented at the Annual Conference of the Australian Association for Research in Education, Perth, December 2001.

\section{References}

Archer, J., Cantwell, R. \& Bourke, S. (1999) University study via an enabling program: Achievement, motivation, and self regulation, Higher Education Research and Development, 18, pp. 31-54.

Biggs, J. (1987a) Student Approaches to Learning and Studying (Hawthorn, ACER).

Biggs, J. (1987b) The Study Process Questionnaire (Hawthorn, ACER).

Biggs, J. \& Collis, K. (1989) Towards a model of school-based curriculum development and assessment. Using the SOLO Taxonomy, Australian Journal of Education.,33, pp. 151-163.

Billet, S. (2001) Knowledge in practice: Re-conceptualising vocational experience, Learning and Instruction, 6, pp431-452.

Cantwell, R. (2001) Learning Theory for Academics: An Introductory model, Teaching Guides, Learning and Development Unit, University of Newcastle. Available online at: http://www.newcastle.edu.au/services/iesd/ publications/eunexus/articles/teaching_guides/

Cantwell, R. \& Grayson, R. (2002) Individual differences among enabling students: A comparison across three enabling programmes, Journal of Further and Higher Education, 26 (3/4), pp293-308.

Cantwell, R., Archer, J. \& Bourke, S. (2001) A comparison of the academic experiences and achievement of university students entering by traditional and non-traditional means, Assessment and Evaluation in Higher Education. 26 (3), pp. 21-34

Cantwell R. \& Hempenstall, P. (2001). Individual differences in university students' conceptions of learning history. Paper presented at the $9^{\text {th }}$ Conference of the European Association for Research on Learning and Instruction, Freiburg, Switzerland, August.

Cantwell, R. \& Moore, P. (1996) The development of measures of individual differences in self-regulatory control and their relationship to academic performance. Contemporary Educational Psychology, 21, pp. 500-517.

Hoskins, S., Newstead, S. \& Dennis, I. (1997) Degree performance as a function of age, gender, prior qualifications and discipline studied, Assessment and Evaluation in Higher Education, 22, pp. 317-328. 
Rawson, M. (2000) Learning to learn: more than a skill set, Studies in Higher Education. 25 (2), pp. 225-238.

Richardson, J. (1994) Mature students in higher education: II. Academic performance and intellectual ability, Higher Education. 28, pp. 373-386.

Scevak, J., Cantwell, R. \& Chan, L. (2002). Individual differences and teacher self-efficacy: A profile of Australian teachers. Paper presented at the 27th Association for Teacher Education in Europe Annual Conference, Warsaw, 24th-28th August 2002

Statsoft, Inc. (2001) STATISTICA for Windows v6.0 [Computer program manual]. Tulsa, OK: StatSoft, Inc. Schommer, M. A. (1993) Epistemological development and academic performance among secondary schools, Journal of Educational Psychology, 85, pp. 406-411.

Schommer, M. A. (1998) The role of adults' beliefs about knowledge in school, work, and everyday life, in: M. C. Smith \& T. Pourchot (Eds) Adult learning and development (New Jersey, Lawrence Erlbaum)

Trowler, P. (1996) Angels in marble? Accrediting prior experiential learning in higher education, Studies in Higher Education, 21, pp. 17-30 